\title{
Uncertainty Error Analysis on Micro Hardness of Al6061-B 4 C Surface Composites Produced by Friction Surfacing
}

\author{
S. Mohanasundaram, S. J. Vijay, Ajay Vasanth. X, P. Ramkumar
}

\begin{abstract}
Friction surfacing is a confined surface modification process of depositing a layer of a consumable tool (Mechtrode) over the base plate (Substrate). This solid-state surfacing opts for dissimilar material and erosion resistant coatings. It is also utilized for localized repairing of worn-out components. In the present study, the hardness of the coated material is compared with the substrate. In this experiment, the Al-B4C composite consumable rod is prepared with Aluminium 6061 alloy and 3, 6, 9,12 and 15 weight \% of $B 4 C$ by stir casting and coated over the Aluminium 6061 alloy plate. The 25-run experiment is conducted for the combination of the rotational speed, traverse speed and axial load. The combined effect of process parameters and the increase in weight \% of $B 4 C$ results in the change in hardness. The hardness of the coating is enhanced by $65 \%$ than the substrate. The uncertainty analysis revealed that it has a good correlation with the hardness standard value and also it has an error of 5\%. The ANOVA analysis concluded that the rotational speed and the weight percentage of the reinforcement improved the microhardness of the coating.
\end{abstract}

Keywords: Friction Surfacing, Error analysis, Al6061, $B_{4} C$, Surface Composite, Hardness

\section{INTRODUCTION}

$S$ urface engineering (SE) is a surface modification process that enhances the properties of the local area, they are divided into gaseous, liquid, molten and solid-state processes. SE methods are classified into nitriding, physical vapour deposition (PVD), chemical vapour deposition (CVD), laser processing, thermal spraying, cold spraying, liquid deposition techniques and friction-based techniques [1]. SE helps in improving the bonding and modifying properties of a substrate on the thin layer surface. On the other hand, the material is coated over the top surface to improve wear/ corrosion resistance and also to repair the damaged parts [2].

Friction based SE includes Friction Stir Surfacing (FSS) and Friction Stir Processing (FSP) techniques. FSP modifies

Revised Manuscript Received on Month xx, 20xx.

S. Mohanasundaram, Department of Mechanical Engineering, Karunya Institute of Technology and Sciences, Coimbatore, India. Email: johnmohana@yahoo.com

S. J. Vijay, Department of Mechanical Engineering, Karunya Institute of Technology and Sciences, Coimbatore, India. Email: vijayjoseph.2001@gmail.com

Ajay Vasanth. X, Department of Mechanical Engineering, Karunya Institute of Technology and Science, Coimbatore 641114, India. Email: vasantajay@gmail.com

P. Ramkumar, Department of Mechanical Engineering, Karunya Institute of Technology and Sciences, Coimbatore, India. Email: ramkumarzeru@gmail.com the microstructure of a surface by deforming, recrystallizing and homogenizing the grain structure. Friction Surfacing (FS) is a solid-state coating process where a substrate is coated with a consumable rod by applying an axial load and rotation to it [3]. This technique of depositing a rotating consumable rod over a solid-state base material enhanced the properties on the top surface of base metal [4]. Fig. 1. exhibits an overview of the process, where a plasticized layer of the rod produced by the frictional heat at its tip is coated on the surface of the base metal [5]. The substrate material is not melted; hence, the substrate is not diluted into the deposit and the configuration of the deposit is like the consumable rod [6].

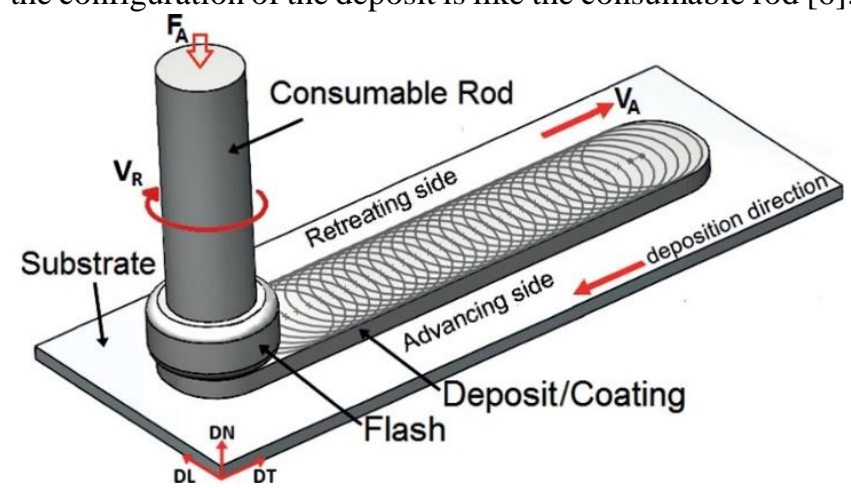

Fig. 1.Friction surfacing Schematic diagram [7]

The consumable rod coating over the substrate is inherently homogenous with improved mechanical strength and adherence. Generally, the layer at the interface continues to be integral, though the resisting load equates the softer material's ultimate tensile strength. However, the integrity of the bond at the edges of the deposit is mostly inadequate and the same has to be cleared out. The quality of the surface depends on the consumable rod that is to be deposited and when a high strength surfacing material (consumable rod) is used, the thickness of the deposit is usually on the lower side [8]. A major dominance of this process is that being a solid-phase process, metallurgically incompatible materials can be fused Unique combinations of material properties can be achieved, which cannot usually be realized in monolithic materials. This reduces the usage of more valuable and strategic content and time [9].

The study of friction surfacing on aluminum alloys with aluminium composite mechtrode investigated the various parameters and their influence on the properties of coated layers. 
The impact of rotational tool speed and traverse speed on coating thickness, width, bonding strength and mechanical properties discussed in friction surfacing of AA5xxx coated on AA6xxx [8] and AA6082 on the AA2024 [10]. The influence of process parameters on coating thickness and width in AA5052 coating on AA5052 [11]. The hardness of the coating is higher than the substrate hardness and equals the consumable rod in the coatings of AA2 xxx on AA5xxx [12]. The fracture toughness of the alloy is enhanced in the AA6082-T6 aluminum alloy on the AA2024-T3 alloy [13]. The literature revealed that there is an opportunity to develop a hard coating over a soft substrate, which is challenging. Hence in this more attempts made to coat $\mathrm{Al} 6061-\mathrm{B}_{4} \mathrm{C}$ on Al6061 using friction surfacing.

The coated surface and substrate are characterised for hardness and error analysis deemed using the estimation values. The error analysis of estimation can surge confidence in selecting the material. The ability and aptness of this method can be applied to several industries.

\section{EXPERIMENTAL PROCEDURE}

\section{A. Fabrication of consumable tool}

Al 6061-T6 plates of dimensions $150 \mathrm{~mm} \times 150 \mathrm{~mm} x$ $10 \mathrm{~mm}$ were used as the substrate in this study. Boron Carbide

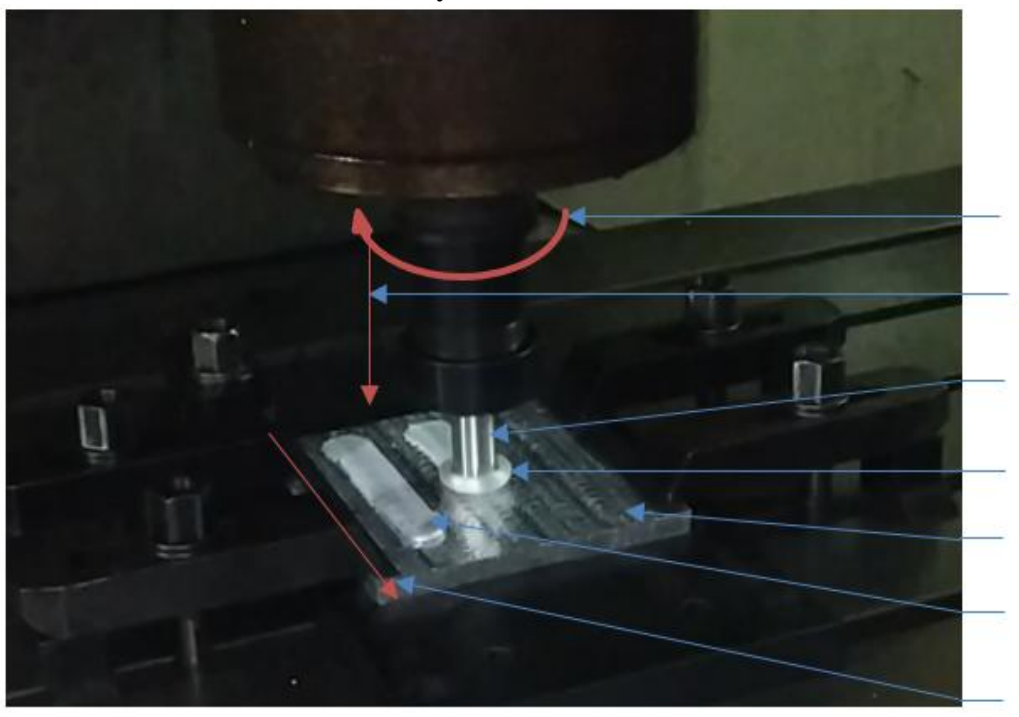

Rotation Direction

Axial Load Direction

Consumable Rod

$\left(\mathrm{Al} 6061-\mathrm{B}_{4} \mathrm{C}\right)$

Flash

Roughly Milled Surface

Coating on $\mathrm{Al} 6061$ - T6

Substrate

Traverse Direction

Fig. 2.Machine setup and operational directions

A Hurco VMX 24 CNC 3-axis Machining center with a spindle speed of $10000 \mathrm{rpm}$ was used to perform friction deposition. The fabricated Al6061- $\mathrm{B}_{4} \mathrm{C}$ consumable rod is allowed to rotate at a speed and hard-pressed on $\mathrm{Al} 6061$ substrate with force the consumable rod is moved in the traverse direction at speed to achieve the finite thickness coating. The coating characters like thickness, width, and the amount of forging depends on the rotational speed, transverse speed, and the axial load.

Fig. 2. shows the friction surfacing machine setup and the process parameters involved (Table-II). It also indicates the operational direction of rotational speed, traverse speed and axial load. The coating integrity and quality depend on the parameters such as tool rotational speed, traverse speed and axial load. Table-II shows the various process parameters and the values for each process parameter derived based on

several trial experiments.

Table-II: Process parameters and levels of experiment to perform the friction deposition

\begin{tabular}{|c|c|c|c|c|c|}
\hline $\begin{array}{c}\text { Process } \\
\text { Parameters }\end{array}$ & $\begin{array}{c}\text { Leve } \\
\mathbf{1 1}\end{array}$ & $\begin{array}{c}\text { Level } \\
\mathbf{2}\end{array}$ & $\begin{array}{c}\text { Level } \\
\mathbf{3}\end{array}$ & $\begin{array}{c}\text { Level } \\
\mathbf{4}\end{array}$ & $\begin{array}{c}\text { Level } \\
\mathbf{5}\end{array}$ \\
\hline $\begin{array}{c}\text { Weight \% of } \mathrm{B}_{4} \mathrm{C} \\
0\end{array}$ & 3 & 6 & 9 & 12 \\
\hline $\begin{array}{c}\text { Rotational Speed } \\
\text { (rpm) }\end{array}$ & 1800 & 1900 & 2000 & 2100 & 2200 \\
\hline $\begin{array}{c}\text { Traverse Speed } \\
(\mathrm{mm} / \mathrm{min})\end{array}$ & 1000 & 1100 & 1200 & 1300 & 1400 \\
\hline Axial Load (kN) & 1 & 2 & 3 & 4 & 5 \\
\hline
\end{tabular}

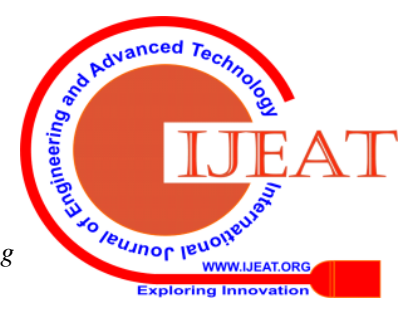




\section{Design of Experiments}

Four parameters with five levels were used for this study. Thus, an L25 array was formed using the Taguchi method, as it provides a simple, consistent, and systematic approach for an optimal DOE to investigate the performance and reliability of the experimental design. The L25 formed array with the process parameters is shown in Table-III.

Table-III: Orthogonal array for experiments

\begin{tabular}{|c|c|c|c|c|}
\hline $\begin{array}{c}\text { S. } \\
\text { No }\end{array}$ & $\begin{array}{c}\text { \% } \\
\mathbf{B}_{\mathbf{4}} \mathbf{C}\end{array}$ & $\begin{array}{c}\text { Rotational } \\
\text { Speed (rpm) }\end{array}$ & $\begin{array}{c}\text { Traverse } \\
\text { Speed }\end{array}$ & $\begin{array}{c}\text { Axial } \\
\text { Load }\end{array}$ \\
\hline 1 & 0 & 1800 & 1000 & 1 \\
\hline 2 & 0 & 1900 & 1100 & 2 \\
\hline 3 & 0 & 2000 & 1200 & 3 \\
\hline 4 & 0 & 2100 & 1300 & 4 \\
\hline 5 & 0 & 2200 & 1400 & 5 \\
\hline 6 & 3 & 1800 & 1100 & 3 \\
\hline 7 & 3 & 1900 & 1200 & 4 \\
\hline 8 & 3 & 2000 & 1000 & 5 \\
\hline 9 & 3 & 2100 & 1300 & 1 \\
\hline 10 & 3 & 2200 & 1400 & 2 \\
\hline 11 & 6 & 1800 & 1100 & 5 \\
\hline 12 & 6 & 1900 & 1200 & 1 \\
\hline 13 & 6 & 2000 & 1000 & 2 \\
\hline 14 & 6 & 2100 & 1300 & 3 \\
\hline 15 & 6 & 2200 & 1400 & 4 \\
\hline 16 & 9 & 1800 & 1300 & 2 \\
\hline 17 & 9 & 1900 & 1100 & 3 \\
\hline 18 & 9 & 2000 & 1200 & 4 \\
\hline 19 & 9 & 2100 & 1000 & 5 \\
\hline 20 & 9 & 2200 & 1400 & 1 \\
\hline 21 & 12 & 1800 & 1400 & 4 \\
\hline 22 & 12 & 1900 & 1300 & 5 \\
\hline 23 & 12 & 2000 & 1100 & 1 \\
\hline 24 & 12 & 2100 & 1200 & 2 \\
\hline 25 & 12 & 2200 & 1000 & 3 \\
\hline
\end{tabular}

\section{Measure of Hardness}

Hardness tests were made on the cross-sectioned coatings. Hardness tests were performed in the Mitutoyo HM-112 Micro-Vickers Hardness Testing Machine shown in Fig. 3. under a load of $2 \mathrm{~N}$. The measurements were carried out at a distance of $200 \mu \mathrm{m}$ between each indentation and a $10 \mathrm{~s}$ indentation dwell time.

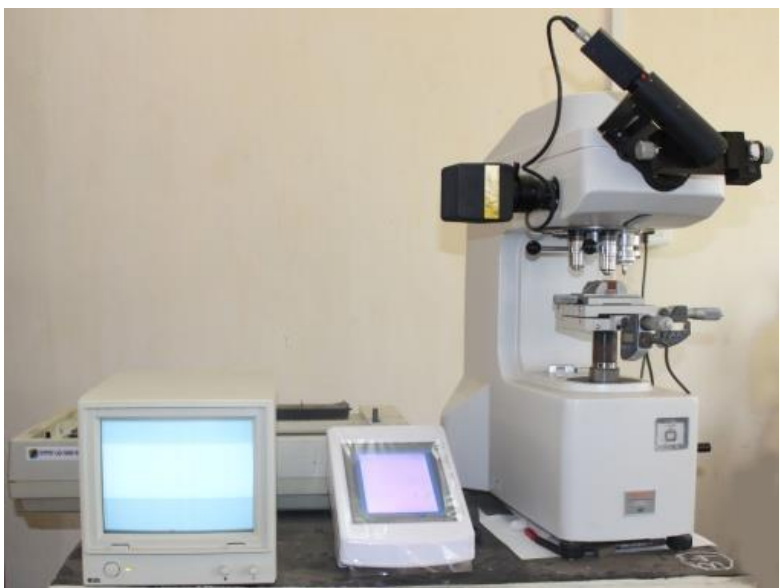

Fig. 3.Vickers Microhardness testing machine

\section{E. Uncertainty and error analysis}

To determine the accuracy of the calculated outcome, the numerical indicator of the measured outcome value should be given. The uncertainty of the measured values in this study was calculated in terms of percentage standard error. Uncertainty analysis invariably represents the precision of the measured value. Thus, performing this analysis ensures that the obtained value does not deviate too much from the true value [14]. Therefore, for the 25 trails, the analysis was performed using the equations (1), (2), (3) and (4). The mentioned equations used for calculating percentage standard error is from the standard JCGM 100:2008 (Type 'A').

$$
\begin{aligned}
& x_{n}=\frac{1}{n} \sum_{i=1}^{n} x_{i} \\
& s^{2}=\frac{1}{(n-1)} \sum_{i=1}^{n}\left(\left(x_{i}-\bar{x}\right)\right)^{2} \\
& \text { Measurement }=\left(x_{i} \frac{ \pm}{s} x_{n}\right) \\
& \text { Error percentage }=\frac{\frac{1}{\sqrt{n}} \times 100}{\sqrt{n}}
\end{aligned}
$$

Where,

$$
\begin{aligned}
& x_{\mathrm{n}}-\text { Uncertainty } \\
& n-\text { Number of observations } \\
& \bar{x}-\text { Arithmetic Average of observation } \\
& s-\text { Standard deviation } \\
& x_{\bar{i}}-\text { Independent repeated observation }
\end{aligned}
$$

\section{RESULT AND DISCUSSION}

The friction between the consumable rod (tool) and the substrate increase in temperature plays a critical and essential role in their bonding. To enhance the friction between mechtrode and substrate, the top surface of the substrate was roughly milled initially. The machined consumable rod was rotated with a frictional force on the substrate. Upon reaching the required rotational speed of the spindle, the consumable rod was made to move along the $\mathrm{z}$-direction. When the consumable rod comes in contact with the substrate,

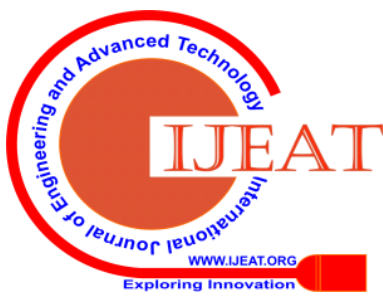


The axial load was used to press the consumable rod into the substrate. This resulted in a rapid increase of force and torque which generated frictional heat at the tip of the consumable rod which in turn produced a flash of a viscoplastic layer, as shown in Fig. 2. The force and torque start to decrease as the mechatrode temperature decreases. Thus, the combined effect of the axial load and the temperature allows the consumable rod to diffuse with the substrate. This formed a bond between the plasticised consumable rod material with the substrate. Heat transferred into the substrate consolidates for the bonding interface and when the consumable rod was moved in the traverse direction at a constant speed, uniform coating thickness, as shown in Fig. 4. can be achieved. The influence of boron carbide particles, temperature and the axial load also increases the hardness of the coating. Microhardness of coated samples under the various combinations of process parameters is given in Table-IV.

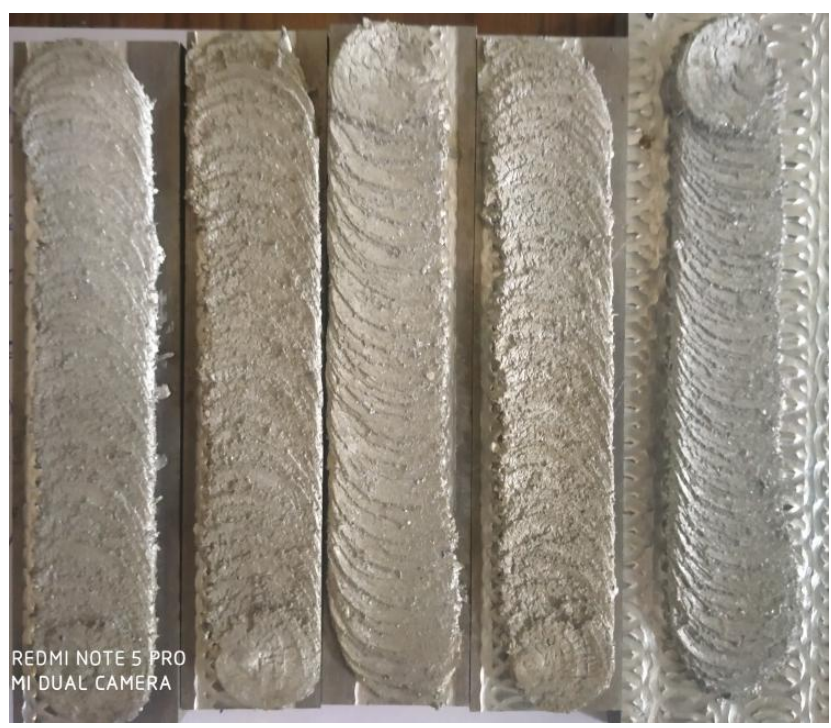

Fig. 4.Al6061-B $\mathrm{B}_{4} \mathrm{C}$ coated over Al6061 substrate

\section{A. Microhardness}

The effect of $\mathrm{B}_{4} \mathrm{C}$ particles weight $\%$ on the microhardness of the coating is presented in Fig. 5. The hardness increased with the amount of reinforcement particles added. The microhardness did not change and almost the same for the 3, 6 and 9 weight $\%$. The maximum microhardness of the Al6061- $\mathrm{B}_{4} \mathrm{C}$ composite coating was $122.7 \mathrm{HV}$. This may be the compound effect of the rotational tool speed and axial force. The increase in tool rotating speed also resulted in increasing the microhardness of the coating shown in Fig. 6. The microhardness is improved $65 \%$ significantly after friction surfacing.

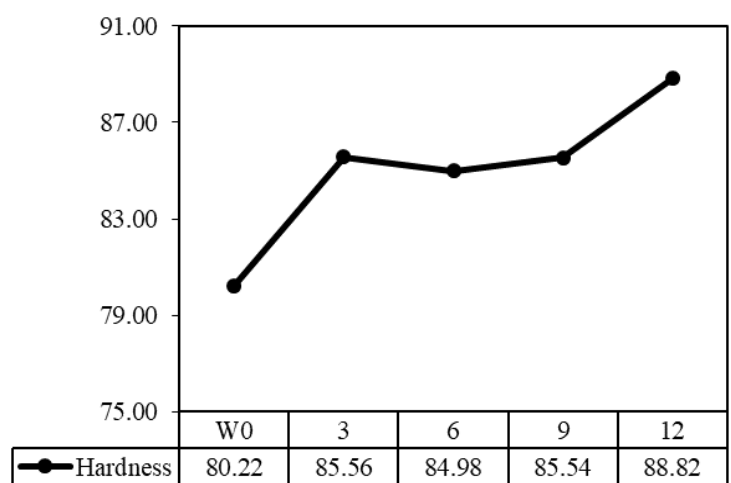

Fig. 5.Effect of $\mathrm{B}_{4} \mathrm{C}$ weight $\%$ on hardness of the coating

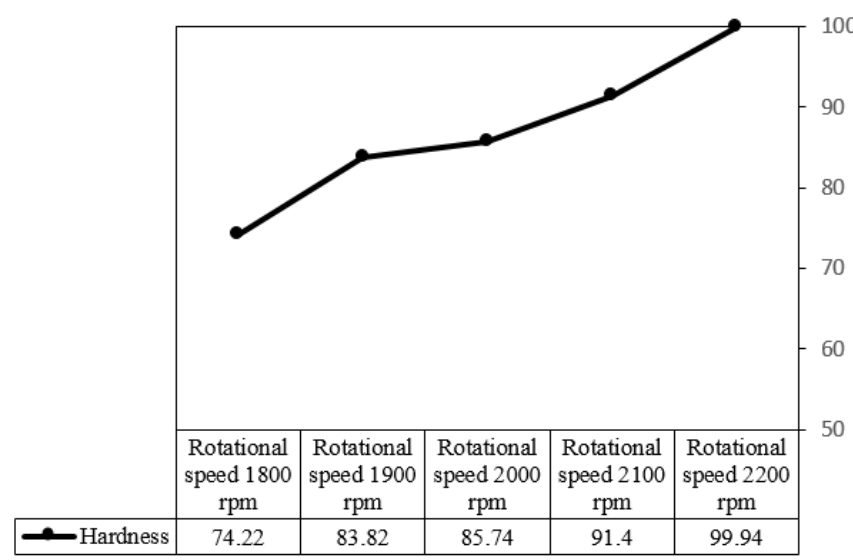

Fig. 6.Effect of rotational speed on microhardness of the coating

\section{B. Uncertainty error analysis of microhardness}

The uncertainty analysis of microhardness was performed using equations (1), (2), (3) and (4)), the value of standard error was $5 \%$ as tabulated in Table-V is well within the standard range of the standard JCGM 100:2008 (Type 'A'). From the obtained standard error, the deviation of individual value was found and has been tabulated in Table 4. And the obtained results were considerably within the permitted $\pm 3 \sigma$ limits. Thus, the uncertainty analysis for the statistical model produced reliable estimation results for the application.

Table-IV: Experimental results on Hardness

\begin{tabular}{|c|c|c|c|c|c|c|}
\hline $\begin{array}{c}\text { S. } \\
\text { No }\end{array}$ & $\begin{array}{c}\text { Wt. \% } \\
\mathbf{B} \mathbf{4}\end{array}$ & $\begin{array}{c}\text { Rotational } \\
\text { Speed } \\
(\mathbf{r p m})\end{array}$ & $\begin{array}{c}\text { Traverse } \\
\text { Speed } \\
(\mathbf{m m} / \mathbf{m i n})\end{array}$ & $\begin{array}{c}\text { Axial } \\
\mathbf{L o a d} \\
(\mathbf{k N})\end{array}$ & $\begin{array}{c}\text { Measure } \\
\mathbf{d} \\
\text { Hardness } \\
\mathbf{u} \mathbf{r}\end{array}$ & Measurement \\
\hline 1 & 0 & 1800 & 1000 & 1 & 73.10 & $73.1 \pm 3.655$ \\
\hline 2 & 0 & 1900 & 1100 & 2 & 76.60 & $76.6 \pm 3.83$ \\
\hline 3 & 0 & 2000 & 1200 & 3 & 76.60 & $76.6 \pm 3.83$ \\
\hline 4 & 0 & 2100 & 1300 & 4 & 96.40 & $96.4 \pm 4.82$ \\
\hline 5 & 0 & 2200 & 1400 & 5 & 78.40 & $78.4 \pm 3.92$ \\
\hline 6 & 3 & 1800 & 1100 & 3 & 98.50 & $98.5 \pm 4.925$ \\
\hline 7 & 3 & 1900 & 1200 & 4 & 95.20 & $95.2 \pm 4.76$ \\
\hline 8 & 3 & 2000 & 1000 & 5 & 79.70 & $79.7 \pm 3.985$ \\
\hline 9 & 3 & 2100 & 1300 & 1 & 85.90 & $85.9 \pm 4.295$ \\
\hline 10 & 3 & 2200 & 1400 & 2 & 68.50 & $68.5 \pm 3.425$ \\
\hline
\end{tabular}




\begin{tabular}{|c|c|c|c|c|c|c|}
\hline 11 & 6 & 1800 & 1100 & 5 & 84.60 & $84.6 \pm 4.23$ \\
\hline 12 & 6 & 1900 & 1200 & 1 & 98.20 & $98.2 \pm 4.91$ \\
\hline 13 & 6 & 2000 & 1000 & 2 & 98.50 & $98.5 \pm 4.925$ \\
\hline 14 & 6 & 2100 & 1300 & 3 & 69.80 & $69.8 \pm 3.49$ \\
\hline 15 & 6 & 2200 & 1400 & 4 & 122.70 & $122.7 \pm 6.135$ \\
\hline 16 & 9 & 1800 & 1300 & 2 & 71.30 & $71.3 \pm 3.565$ \\
\hline 17 & 9 & 1900 & 1100 & 3 & 122.00 & $122 \pm 6.1$ \\
\hline 18 & 9 & 2000 & 1200 & 4 & 69.60 & $69.6 \pm 3.48$ \\
\hline 19 & 9 & 2100 & 1000 & 5 & 75.80 & $75.8 \pm 3.79$ \\
\hline 20 & 9 & 2200 & 1400 & 1 & 89.00 & $89 \pm 4.45$ \\
\hline 21 & 12 & 1800 & 1400 & 4 & 103.60 & $103.6 \pm 5.18$ \\
\hline 22 & 12 & 1900 & 1300 & 5 & 67.10 & $67.1 \pm 3.355$ \\
\hline 23 & 12 & 2000 & 1100 & 1 & 63.20 & $63.2 \pm 3.16$ \\
\hline 24 & 12 & 2100 & 1200 & 2 & 79.10 & $79.1 \pm 3.955$ \\
\hline 25 & 12 & 2200 & 1000 & 3 & 91.10 & $91.1 \pm 4.555$ \\
\hline
\end{tabular}

surface.

\section{REFERENCES}

1. "Coating and Surface Engineering." [Online]. Available: twi-global.com/what-we-do/research-and-technology/technologies/co ating-and-surface-engineering/home.aspx.

2. "Surface Modification - an overview | Science Direct Topics." [Online]. Available: https://www.sciencedirect.com/topics/ materials-science/surface-modification.

3. R. M. Miranda, J. Gandra, and P. Vilaça, "Surface Modification by Friction Based Processes," Modern Surface Engineering Treatments, May 2013.

4. J Gandra, H.Krohn, R.M.Miranda, P. Vilaca, L. Quintino, J.F. dos Santos. J. of Material Processing Technology. 214(2014) 1062-1093.

5. S. Janakiraman, Jayachandra Reddy, Sathish V Kailash, Udaya Bhat K. Surface. Materials science forum (2012) Vol. 710 pp. 258-263.

6. Godwin Barnabas, Parameters Optimization in Friction Surfacing, Chemical and Materials Engineering 2(6): 127-136, 2014

7. J. C. Galvis et al., "Assessment of Process Parameters by Friction Surfacing on the Double Layer Deposition," Materials Research, vol. 21 , no. 3, 2018.

8. J. Galvis, P. Oliveira, M. Hupalo, J. Martins, A. Carvalho, Influence of friction surfacing process parameters to deposit AA6351-T6 over AA5052-H32 using conventional milling machine, J. Mater. Process. Technol. 245 (2017) 91-105

Table-V: Error percentage for the hardness

\begin{tabular}{|l|c|}
\hline Standard Deviation & 0.2638 \\
\hline Journal standard deviation & 0.0725 \\
\hline Standard error & 0.0528 \\
\hline Standard Error percentage & $5 \%$ \\
\hline
\end{tabular}

\section{Analysis of Variance}

ANOVA analysis using Minitab was performed to study the effect of various process parameters on microhardness. ' $F$ ' values obtained from ANOVA provided the most significant process parameter. The ANOVA results are tabulated in Table-VI, and it was evident that the contribution of rotational speed was $51.85 \%$ and reinforcement was $24.11 \%$ towards microhardness of surface. Similarly, the effect of traverse speed and the axial load was relatively low.

Table-VI: ANOVA analysis result for hardness

\begin{tabular}{|c|c|c|c|c|c|c|}
\hline Source & DF & Seq SS & Adj MS & F & P & \% Contribution \\
\hline $\mathrm{B}_{4}$ C Wt. \% & 4 & 647.3 & 323.65 & 0.09921 & 0.75621 & 24.11 \\
\hline $\begin{array}{c}\text { Rotational } \\
\text { Sneed }\end{array}$ & 4 & 1392 & 696 & 0.15423 & 0.95873 & 51.85 \\
\hline $\begin{array}{c}\text { Traverse } \\
\text { Sneed }\end{array}$ & 4 & 234 & 117 & 0.36225 & 0.55438 & 8.72 \\
\hline Axial load & 4 & 276.6 & 138.3 & 0.25214 & 0.62134 & 10.30 \\
\hline Error & 8 & 134.6 & 67.3 & & & 5.01 \\
\hline Total & 24 & 2684.5 & & & & \\
\hline
\end{tabular}

\section{CONCLUSIONS}

From the studies conducted on friction surfacing, the following conclusions can be obtained

1. Friction surfacing has improved the hardness by $65 \%$ when compared with the substrate.

2. The measured hardness result quality validated with Type ' $A$ ' uncertainty analysis. It is observed that the evaluated result displays good connectivity with hardness standard value along with the maximum uncertainty value of \pm 6.135 Hv.

3. The analysis also reveals that it has an error of $5 \%$.

4. ANOVA analysis inferred, the contribution of rotational speed was $51.85 \%$ and the reinforcement was $24.11 \%$ and they also significantly improved the microhardness of the

9. Rao K P, Sankar A, Rafi H K, Ram G D J, Reddy G M. Friction surfacing on nonferrous substrates: A feasibility study [J]. International Journal of Advanced Manufacturing Technology, 2012, 65: 755-762.

10. H. Sakihama, H. Tokisue, K. Katoh, Mechanical properties of friction surfaced 5052 aluminum alloy, Mater. Trans. 44 (2003) 2688-2694.

11. H. Tokisue, K. Katoh, T. Asahina, T. Usiyama, Mechanical properties of 5052/ 2017 dissimilar aluminum alloys deposit by friction surfacing, Mater. Trans. 47 (2006) 874-882.

12. J. Gandra, D. Pereira, R. Miranda, R. Silva, P. Vilaça, Deposition of AA6082-T6 over AA2024-T3 by friction surfacing-Mechanical and wear characterization, Surf. Coating. Technol. 223 (2013) 32-40.

13. Gandra, D. Pereira, R. Miranda, P. Vilaça, Influence of process parameters in the friction surfacing of AA 6082-T6 over AA 2024-T3, Procedia CIRP 7 (2013) 341-346.

14. S.P. Leo Kumar, "Measurement and uncertainty analysis of surface roughness and material removal rate in micro turning operation and process parameters optimization”, Measurement 140 (2019) 538-547.

\section{AUTHORS PROFILE}

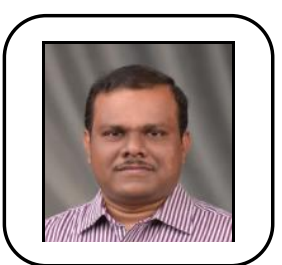

S. Mohanasundaram received his bachelor degree in mechanical engineering in in 2004 from Bharathiar University, Coimbatore and master degree in Engineering Design in 2011 in Karunya University, Coimbatore. He is working as an Assistant Professor in Karunya Institute of Technology and Sciences, Coimbatore. His area of research includes Friction stir welding,

Processing and Surfacing.

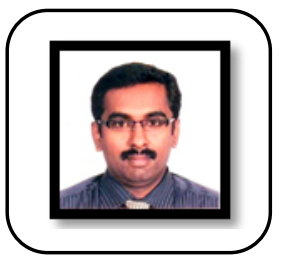

S. J. Vijay received his bachelor degree in mechanical engineering in 2002 from Karunya Institute of Technology and Sciences, Coimbatore and master degree in CAD/CAM in 2005 from Karunya Institute of Technology and Sciences, Coimbatore. He received Ph.D. degree in mechanical engineering from Anna University, India. He is working as an Associate Professor in Karunya Institute of Technology and Sciences, Coimbatore. His research interests include Friction stir welding, Processing, Surfacing and Metal Matrix Composites. He has published papers in many refereed international journals and conferences for his highest level of achievement. 


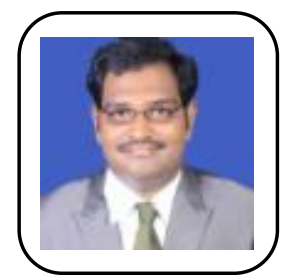

Ajay Vasanth. $\mathbf{X}$ received his bachelor degree in mechanical engineering in 2011 from SASTRA, Deemed to University, India. He received his master degree in mechanical engineering in 2013 from Karunya Institute of Technology and Science, Deemed to be University, India. His research interests include finite element analysis, vibrations and control systems. He is an assistan Professor in the Department of Mechanical Engineering, Karunya Institute of Technology and Science, Deemed to be University, India. His research area includes vibration, finite element analysis and control systems.

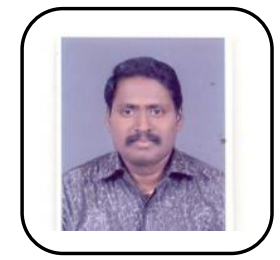

P. Ramkumar received his Master degree in Engineering Design in 2007 from Karunya Institute of Technology and Sciences, Deemed to be University, Coimbatore. His research interests include Friction Surfacing and Metal Matrix Composites. 